


\title{
Formas de evaluación de los aprendizajes en nivel superior: Notas a partir de una investigación narrativa en la Facultad de Psicología de la Universidad Nacional de Mar del Plata
}

\author{
Forms of evaluation of the learning in superior level: Notes from a narrative \\ research in the Faculty of Psychology of the National University of Mar del Plata
}

\author{
Mario Adrián Recalt \\ Especialista en Docencia Universitaria \\ Universidad Nacional Mar del Plata \\ Mar del Plata, Argentina \\ Correo electrónico: adrianrecalt@hotmail.com \\ Francisco Ramallo \\ Doctor en Humanidades y Artes con mención en Ciencias de la Educación (UNR) \\ Docente investigador grupo de Investigaciones en Educación y Estudios Culturales del Centro de Investigaciones Multidisciplinares en Educación \\ (CIMED) \\ Universidad Nacional Mar de Plata, Mar del Plata, Argentina \\ Correo electrónico: franarg@hotmail.com
}

Recibido: 25 de agosto de 2017. Aceptado: 30 de septiembre de 2017

\begin{abstract}
Cómo citar este artículo
Recalt, M.A., y Ramallo, F., (2018). Formas de evaluación de los aprendizajes en nivel superior: Notas a partir de una investigación narrativa en la Facultad de Psicología de la Universidad Nacional de Mar del Plata. Espiral, Revista de Docencia e Investigación 8(1), 11 - 30.
\end{abstract}

\section{Resumen}

Objetivo. Interpretar los relatos de profesores sobre la enseñanza y específicamente sobre la evaluación de los aprendizajes en la carrera de Psicología de la Universidad Nacional de Mar del Plata.

Metodología. Se optó por un enfoque cualitativo desde una perspectiva narrativa concentrada en la comprensión de los significados que los participantes de la investigación otorgan a las prácticas evaluativas. Para recolección de datos se privilegió la técnica de entrevistas semiestructuradas combinadas con materiales, instrumentos y prácticas de evaluación de los aprendizajes elaborados y empleados por los profesores seleccionados. El diseño y la puesta en práctica de los sistemas de evaluación propuestos por cada uno de los docentes entrevistados tienden a ligarse a las valoraciones particulares que cada uno de ellos verbaliza sobre la evaluación de los aprendizajes.

Resultados. Variables como la complejidad, la articulación y el trazado de las formas de evaluación son distintas en función de que las mismas sean consideradas de mayor o menor importancia dentro de las actividades pedagógico docentes. Reconocemos además una recu- rrencia similar donde evaluación, enseñanza y aprendizaje suceden casi en simultáneo y los cambios en las prácticas refieren a modificaciones más amplias desde el currículo y la didáctica.

Palabras clave: Enseñanza, evaluación de los aprendizajes, investigación narrativa, profesores.

\section{Abstract}

The objective of this article is to interpret the teachers' stories about teaching and specifically about the evaluation of learning in psychology at the National University of Mar del Plata.

Metodology. We chose a qualitative approach from a narrative perspective focused on the understanding of the meanings that research participants give to evaluative practices. For data collection, the technique of semi-structured interviews combined with materials, instruments and practices for evaluating the learning developed and used by the selected teachers was privileged. The design and implementation of evaluation systems proposed by each of the teachers interviewed tends to be linked to the particular assessments that each one of them speaks about the evaluation of learning. 
Resultados. In such a way that variables such as complexity, articulation and the layout of the forms of evaluation are different depending on whether they are considered of greater or lesser importance within the teaching pedagogical activities. We also recognize a similar recurrence where evaluation, teaching and learning happen almost simultaneously and changes in practices refer to broader changes from the curriculum and didactics.

Keywords: Evaluation, learnings, narrative research, teachers.

\section{Introducción}

El presente artículo es el resultado de una investigación sobre las formas de evaluación de los aprendizajes, a partir de los relatos de profesores de la Facultad de Psicología de la Universidad Nacional de Mar del Plata (en adelante UNMdP) (Recalt, 2018). Particularmente, desde una investigación cualitativa con una perspectiva narrativa (Yedaide, Álverez y Porta, 2015) comparamos aquí las concepciones de enseñanza manifestadas en las diferentes maneras de evaluar de estos docentes, con la intención de comprender rupturas y continuidades en sus trayectorias respecto de sus formas de evaluar. El objetivo general de este trabajo, entonces, consiste en interpretar los relatos de profesores sobre la enseñanza y la evaluación de los aprendizajes en la carrera de Psicología de la UNMdP.

Estas intenciones nos recuerdan que la docencia universitaria ha sido estudiada e interpretada mayoritariamente a partir de las normativas y disposiciones burocráticas, desde una mirada macroanalítica y tecnocrática. Sin embargo, desde la Nueva Agenda de la Didáctica (Litwin, 1998) ha quedado propuesta una perspectiva narrativa, si se quiere biográfica, que recupera las prácticas y las vidas de los sujetos en la investigación educativa, que es la que pretendemos abordar en la presente investigación. Entendemos en consecuencia que la narrativa es la cualidad estructurada de la experiencia entendida y posible de verse como un relato, que implica formas de construir sentido, a partir de acciones temporales personales por medio de la descripción y análisis de los datos biográficos. Es una particular reconstrucción de la experiencia, por la que mediante un proceso reflexivo se da significado a lo sucedido o vivido (Bolívar y Fernández, 2001). En efecto, no hay registros narrativos únicos, más bien múltiples y polifónicos que combinan el relato con el conocimiento y con la comprensión de lo referido (Porta, 2017).

Especialmente desde los aportes conceptuales y metodológicos del Grupo de Investigadores en Educación y Estudios Culturales (GIEEC) reflexionamos sobre una serie de categorías como la identidad de los docentes, los "profesores memorables", la "pasión" en el aula, "el don docente", el docente que "conmueve", las afecciones del "ser docente" y las dimensiones ético/morales de la docencia secundaria (Yedaide, Álvarez y Porta, 2015). El estímulo en este caso es recuperar la temática de la evaluación de los aprendizajes desde el significado que los docentes le dan. A partir de valorar a través del relato sus biografías, vivencias, emociones y experiencias de vida, que luego serán parte de su identidad en el aula (Porta, Sarasa y Álvarez, 2010).

En síntesis, la perspectiva narrativa abordada conduce a aproximar tentativamente relaciones entre los aspectos de la práctica destacados por los docentes y sus biografías personales y profesionales. Las categorías centrales que se definen en la Nueva Agenda de la Didáctica ayudan a reconocer las buenas acciones docentes, identificadas por la intuición, la sabiduría práctica y la espontaneidad, según el nuevo marco de pensamiento para el estudio de las prácticas de la enseñanza propuesto por Litwin (2008). Aquí una referencia ineludible es la obra de Philip Jackson (2002) que jerarquiza el lugar de la narrativa en la enseñanza, haciendo referencia a la función "epistemológica" de los relatos, y aludiendo a que muchos de ellos contienen el conocimiento que se enseña en el mundo exterior. No solo eso, sino que constituyen de por sí aquellos saberes que deseamos que nuestros alumnos aprendan. 


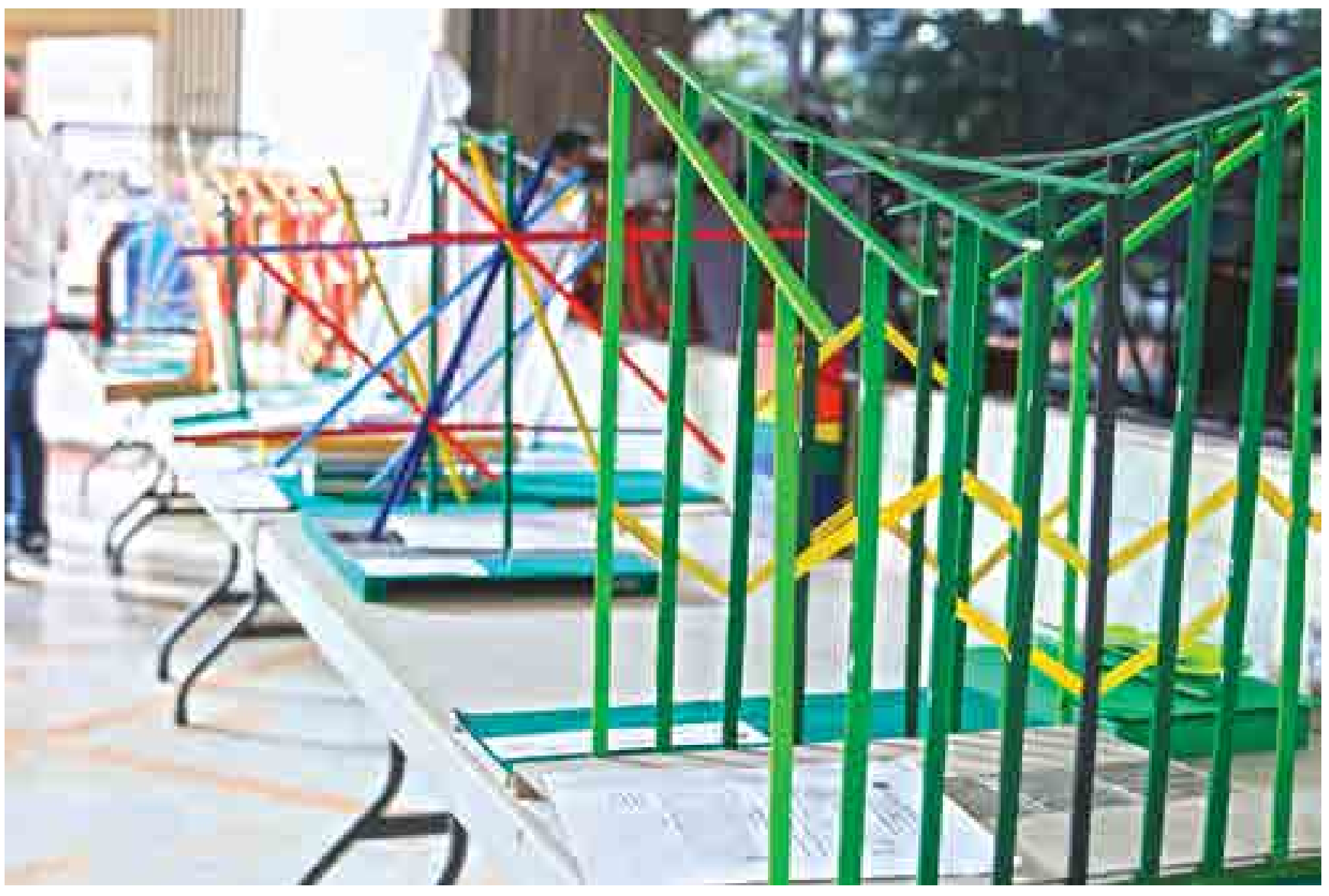

Recordamos brevemente que en la investigación educativa la narrativa permite generar y reconstruir significados. En tanto forma de representación situada, la narrativa (re)construye, cuenta, argumenta y explica (Mc Ewan y Egan, 1998). Se considera que la narrativa es apropiada para la especificidad y complejidad de los contextos educativos. En este marco, las narrativas sirven para reconstruir las experiencias y dar sentido a las acciones. Su utilidad, tanto para describir o explicar significados personales y sociales, como para comprender la trama de las actividades de los docentes, de los estudiantes y de las instituciones, es sumamente apreciada en la literatura educativa. Lo que podrían considerarse meras "anécdotas" son complejas tramas de vidas, aspiraciones y relaciones sociales que siempre ocultan sorpresas.

El valor de los aportes de la narrativa en la investigación educativa, en tanto constructora del sentido interior y exterior de la realidad ha sido ampliamente explorado en la literatura (Bruner, 1998). Sus elaboraciones "densas" ayudan a reconstituir el interior y el exterior de los hechos, el pensamiento y la acción. McEwan y Egan (1998, p. 18) destacan el papel que cumplen las narrativas en la comprensión de cuestiones educativas. Las narrativas (al ordenar las experiencias) las hacen inteligibles para los propios agentes y para el resto de la comunidad educativa porque las reconstruyen y resignifican. Las historias constituyen por sí mismas instrumentos de interpretación al relatar y explicar o argumentar a la vez. Asimismo, para algunos autores, las narrativas son también una forma de cerrar la brecha entre lo público y lo privado. Por otra parte, las narrativas emergen como productoras de teorías de la enseñanza y del aprendizaje.

Es por ello que pretendemos recuperar las voces de profesores para que, desde su propia perspectiva, puedan dar cuenta de cómo entienden sus realidades (Bolívar y Fernández, 2001, p. 66). 
"Se necesita comprender las formas de pensar, los valores y los conceptos que están detrás de la buena enseñanza e individualizar las actitudes y tendencias, que sirven de base al buen hacer de los profesores" (Bain, 2012). El discurso de la afectividad y las emociones en la educación encuentra registros relativamente novedosos, intermitentes y aún poco sistematizados en la literatura académica. Teñido del descrédito que la ciencia más positivista adscribe casi mecánicamente a todo lo que se resiste a la comprobación experimental, este lenguaje va emergiendo tímidamente según vamos enfrentando las desventuras de los enfoques tecnicistas, que finalmente muestran grandes limitaciones a la hora de traducir sus aspiraciones al describir la realidad.

La cuestión de la evaluación de los aprendizajes aparece como una inquietud creciente entre los diferentes actores ligados a la problemática de la pedagogía universitaria. Existe una mayor reflexión de las relaciones enseñanzaaprendizaje-evaluación; como así también es más notorio el desconocimiento de los docentes sobre la naturaleza de esas relaciones; de las condiciones de validez que permitirían una buena evaluación; de las herramientas necesarias para asegurar la consistencia entre los enfoques pedagógicos y las prácticas de evaluación; etc. (Camilioni y Cols, 2010). Diferentes autores han destacado que existe un gran consenso entre los teóricos e investigadores educacionales, acerca del poder explicativo que tienen determinados factores para dar cuenta del fenómeno educativo. Entre estos se encuentran las llamadas "prácticas pedagógicas del profesor", entendiendo por estas el conjunto de acciones que reflejan aspectos de su saber docente. De manera tal que existe un consenso en remarcar la relevancia del estudio acerca del pensamiento del profesor, centrados en torno a las teorías personales que los docentes se forman sobre la práctica educativa (Montero, 2001).

Por su parte las investigaciones sobre evaluación educativa en el nivel superior configu- ran un importante campo de conocimiento en constante desarrollo, constituyendo un terreno donde se han abordado distintos temas. Cols (2009) enumeró los siguientes: naturaleza y las funciones de la evaluación; papel del docente y el alumno en este proceso; vínculos entre currículo y evaluación; estrategias e instrumentos de evaluación y sus requisitos; relación entre objetivos y evaluación; problema de la calificación y las distintas alternativas posibles han proliferado múltiples perspectivas.

Junto a los desarrollos arriba mencionados, en los últimos años se ha visibilizado el lugar que ha venido ocupando la evaluación de los aprendizajes, en tanto que instrumento de constatación de unos conocimientos que debieron ser incorporados durante el transcurso de la enseñanza. Función que se llevaría a cabo a través de un acto único al final del proceso, utilizando para ellos técnicas de medición (Celman, 1998). De aquí al evaluar, el profesor pone en juego su concepción con respecto a lo que considera que es aprender y enseñar. De manera tal que al evaluar se ponen de manifiesto sus teorías implícitas sobre la evaluación de los aprendizajes. Tal como lo enuncia Celman (2003), será muy distinto si las evaluaciones: a) son el medio de acreditar, a través de un proceso de medición (exámenes escritos, múltiple chois) si los alumnos aprendieron o no lo que la cátedra les enseñó y b) son parte integrante de la propuesta pedagógica - didáctica. Desde este último punto, la evaluación debe actuar al servicio del conocimiento y del aprendizaje (Álvarez, 2001), o al decir de Bain (2007) se tratara de que la evaluación se centre en el aprendizaje y no en el rendimiento.

\section{Metodología}

En esta investigación sobre los relatos de profesores acerca de la evaluación de los aprendizajes en la Facultad de Psicología de la UNMdP se optó por un enfoque cualitativo, desde una perspectiva narrativa concentrada en la comprensión de los significados que los participantes de 
la investigación otorgan a las prácticas evaluativas. Para recolección de datos se privilegiará la técnica de entrevistas semiestructuradas combinadas con materiales, instrumentos y prácticas de evaluación de los aprendizajes elaborados y empleados por los profesores seleccionados.

La comprensión de las concepciones de enseñanza acerca de la evaluación de los aprendizajes, construidas por los docentes, implica hacer referencia a los principios fundantes, epistemológicos, ontológicos y conceptuales establecidos a lo largo de la historia personal y cultural. Se trata de develar los significados que los docentes otorgan a las prácticas evaluativas, desde el giro hermenéutico en la investigación educativa. No buscando leyes como lo hace la ciencia experimental, sino buscando significaciones como una ciencia interpretativa. Al respecto recuperamos la idea, tomando a Gadamer (2001), de que la experiencia se presenta en un contexto de relaciones entre sujetos que comparten una actividad. El contexto está conformado por estructuras culturales e históricas en cuya dinámica se crea el sentido otorgado por los sujetos participantes, quienes a través del lenguaje generan procesos comunicativos, los cuales se traducen en una praxis que a su vez se traduce en actos intersubjetivos comprensivos que constituyen el significado. EI lector-intérprete que intente comprender un texto se traslada al pensamiento del autor del texto con el fin de participar en el develamiento de esos significados. Con el objeto de conocer dicho pensamiento, utilizamos una entrevista semiestructurada. Para su diseño se consideró el referente teórico, los objetivos y la característica de los participantes. La muestra quedó constituida por tres docentes de la carrera de Psicología de la Universidad de Mar del Plata.

Por tanto, secuenciamos tres momentos o etapas recursivas. La primera de ellas estuvo asociada a nuestro pequeño trabajo de campo, en la selección de los profesores para entrevistar y la confección de los instrumentos de esta investigación. A su vez este momento estuvo caracterizado por nuestro acercamiento a la investigación educativa, especialmente a partir de la lectura del marco conceptual y metodológico de la investigación narrativa. En relación con los entrevistados, elegimos un grupo de tres profesores que ejercen la docencia desde hace más de veinte años en la Facultad de Psicología de la Universidad Nacional de Mar del Plata: titular de la cátedra Psicología Jurídica, perteneciente a una de las áreas profesionales en el cuarto atados, y especificamente por el onversaciones con los docentes entrevistados, y especificamente por la ño de la carrera (entrevista 1); adjunto de la cátedra Epistemología de la Psicología, perteneciente al cuarto atados, y especificamente por el onversaciones con los docentes entrevistados, y especificamente por la ño de la carrera (entrevista 2) y titular de la cátedra Núcleos Problemáticos I, asignatura obligatoria que se puede cursar en cualquier momento de la carrera (entrevista 3).

El segundo momento de nuestra investigación estuvo caracterizado por las conversaciones con los docentes entrevistados, y específicamente por la recolección de datos a través de la toma de entrevistas. Nos concentramos, además, en el análisis de las trayectorias profesionales de los docentes. Y, para terminar, nos concentramos en el análisis de los datos y en la escritura de este trabajo final, profundizando un análisis de relaciones entre algunas categorías emergentes, tal como proponen Hubbard y Power (1999), a partir de rastrear categorías claves para la discusión y los hallazgos de este trabajo.

Entonces, en un nivel general, este trabajo se asoció inicialmente a una perspectiva narrativa, una metodología cualitativa, que permite conocer aspectos ligados a lo sutil y lo espontáneo de la educación. En este sentido, por un lado, remitimos a la narrativa como cualidad estructurada de la experiencia entendida como un relato; y por otro, advertimos que corresponde a un enfoque de investigación en sí mismo, con pautas y formas de construir sentido a partir de acciones temporales personales. La narra- 
tiva resulta así apropiada para la especificidad, complejidad e intransferibilidad de los relatos de los procesos educativos. Este enfoque permite reconstruir y reorganizar la experiencia a través de un relato asumiendo la complejidad de la tarea del investigador como intérprete, puesto que establece un diálogo con el texto sin excluir el reconocimiento de sí mismo como portador de significados y como coautor de la narración, pues formamos parte del propio proceso de investigación.

Debemos distinguir aquí entre la narrativa como relato, la narrativa como enfoque y la narrativa como dispositivo formativo. El relato mismo no basta y se hace útil la necesaria distinción que existe en la lengua inglesa entre life story (relato de vida) y life history (historia de vida). En la perspectiva que asumimos, el enfoque biográfico-narrativo hace necesario la reconstrucción del relato en un nuevo texto por parte del investigador. Este texto aporta el contexto histórico, social, pasando de la life story a la life history, como bien diría Goodson (1992). De ahí que, para algunos, el enfoque biográfico narrativo se sitúa más allá del enfrentamiento paradigmático entre lo cuantitativo y cualitativo, de manera que no se trataría de una metodología cualitativa más. Por nuestra parte no entraremos en esta discusión; $y$, considerando la especificidad del enfoque biográfico-narrativo nos situaremos en la tradición de las metodologías cualitativas. Se llevará a cabo a través de etapas que contemplan el abordaje al material acerca de las categorías, las biografías y las investigaciones realizadas.

Es por medio de la narratividad que se producen aprendizajes de copertenencia. El interés de esta perspectiva parte de la hermenéutica y el objeto de este tipo de investigación cualitativa no es la generalización formal, sino poner de manifiesto lo singular. A través de estos registros se intenta lograr aportes conceptuales que atiendan a la diversidad de las prácticas de enseñanza. En este recorrido lo biográfico recupera así otro territorio, donde se construyen tramas de significación que colaboran en comprender cómo actúan los sujetos, escampándonos de enfoques normativos y de racionalidades retrospectivas. Reflexionar en estos términos demuestra que las investigaciones de carácter sociológico o de miradas macrohistóricas y las descripciones de la docencia caracterizan a los abordajes sobre nuestro objeto dejaron velada una perspectiva biográfica y microanalítica, necesaria y esclarecedora para comprender los diversos fenómenos sociales que se desarrollaron en la docencia universitaria. Entre los extremos de una reducción tipológica del estudio como un todo homogéneo y coherente que simplificaría la riqueza del objeto y una casuística que nos encerraría en la biografía individual de diferentes sujetos, preferimos abordar a los sujetos como personas que, en un contexto político, económico y social dado, actúan en relaciones sociales específicas a partir de las cuales toman sus decisiones, asumiendo una racionalidad históricamente producida.

\section{Resultados}

Escasas son las investigaciones que se abocan al estudio de la docencia en la Facultad de Psicología de la UNMdP. Mucho más escasos los que abordan la cuestión del pensamiento docente (a través de sus narrativas) al llevar el currículo a la práctica, y específicamente a la evaluación de los aprendizajes. En una búsqueda realizada recientemente por Luis Moya (2012) acerca de la formación de los psicólogos se hallaron antecedentes aislados: un libro sobre la historia de la carrera de Psicología realizado en 1994, un trabajo inédito de dos profesores que caracterizan el surgimiento de esta carrera en Mar del Plata en 1983 y un artículo de dos referentes locales (Vilanova y Di Doménico, 1999). Específicamente sobre la evaluación de los aprendizajes en la Facultad de Psicología de la UNMdP se encuentra como antecedente un trabajo de Bakker y López (2010), quienes indagan desde una perspectiva didáctica los instrumentos de evaluación implementados en la asignatura Biología Humana. 


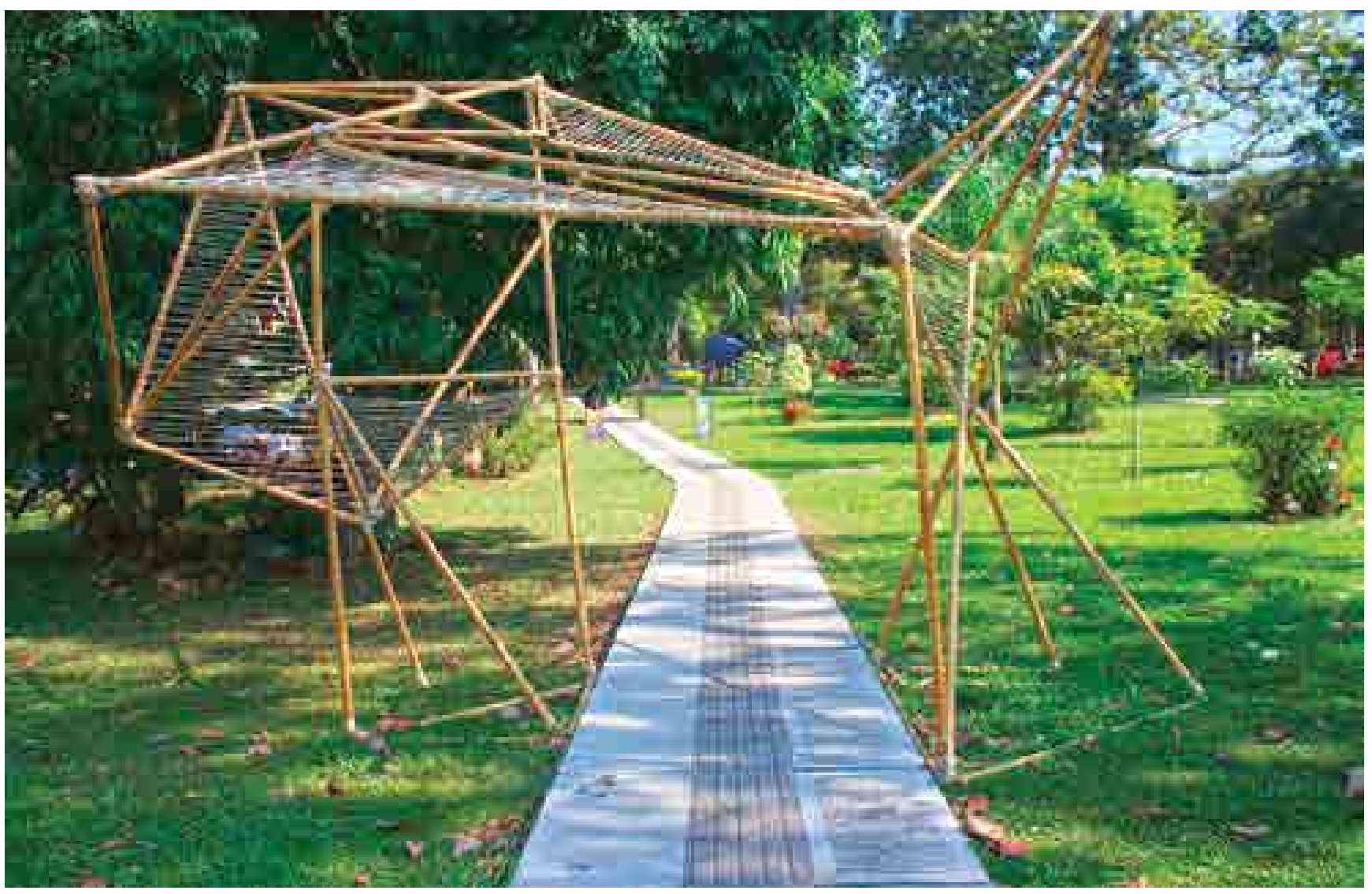

Proyecto Estructura de Bambú.

No obstante, la escasez de trabajos, podemos decir que gran parte de los docentes y titulares de cátedra de la Facultad de Psicología son psicólogos de profesión (o provenientes de profesiones vecinas) o investigadores. Es decir, que han asumido la cátedra según su carrera profesional de origen. Su formación docente está basada fundamentalmente en su experiencia como alumno. Así tal como señala Marrero (1993) se corre con la suerte de que se reproduzcan en el aula los mismos modelos de enseñanza y los mismos sistemas de evaluación con los que ellos fueron formados y evaluados en su época de estudiante. Por lo tanto, podemos pensar que la escasez de estudios en el área, retacea un conocimiento de mucho valor para desarrollar un replanteo del trabajo docente de los profesores universitarios, quienes deben enfrentar el escenario universitario de hoy, caracterizado por el acelerado avance y transformación del conocimiento, y su efímera obsolescencia, la progresiva masificación de la educación superior y la heterogeneidad del alumnado (De Vincenzi, 2009).

En una primera instancia, a partir de entrevistas en profundidad, analizamos los relatos destacando cuatro ejes: a) el concepto general de la evaluación de los aprendizajes, b) las funciones otorgadas a la evaluación, c) las técnicas e instrumentos de la evaluación que emplean los docentes $y, d$ ) la articulación de la evaluación con el currículo. Luego de entrecruzar estas variables, en una segunda instancia hacemos dialogar a los diferentes relatos y enunciamos algunas consideraciones comparativas.

\section{La evaluación procedimental (E1)}

\section{a). Concepto general de la evaluación de los aprendizajes}

Parecen convivir en el relato de la E1 dos grandes formas de concebir la evaluación de los aprendizajes, que a la vez se solapan con 
dos grandes formas de pensar la cuestión de la enseñanza y el aprendizaje. Por un lado, aparece la tendencia a pensar estos procesos como formas de control externo hacia los estudiantes, donde la calificación es una cuestión central y por otro lado una concepción que tiende a pensar la evaluación como un proceso más integral que se articula con los procesos de aprendizaje y de enseñanza. Si bien ella tiende a identificarse más cercanamente con esta segunda forma de concebir los procesos, podemos ver que recursivamente redunda en trazos de ambas formas de concepción. Es interesante que el relato parece orquestarse sin que E1 registre toma de conciencia de disonancias.

E1 valora de manera positiva la evaluación de los aprendizajes y considera que debe otorgársele un importante lugar dentro de los procesos de enseñanza y aprendizaje "Me parece que la evaluación siempre es importante, tanto para poder ver el proceso que realiza el alumno, como también la responsabilidad que tiene el docente" (E1).

En su discurso podemos ver, que por momentos, piensa la evaluación como un proceso donde no se valora exclusivamente al estudiante, sino también otros componentes intervinientes. De la misma manera tiende a concebir el aprendizaje, como un logro y una responsabilidad mutua entre docentes y estudiantes:

Creo que la evaluación tiene que ser mutua, entre los dos, porque cuando nosotros definimos que el aprendizaje en sí convoca tanto al alumno como el docente y que se nutren, también tienen que ser evaluadas ambas instancias, es decir, ambas partes que integran este dúo (E1).

Asimismo es interesante que a la hora de fundamentar esta idea, utilice argumentos que se emparentan más con una concepción de la evaluación que parece menos integral, donde por ejemplo la evaluación se reduce a la situación de examen y además utilizando un criterio calificacionista y cuantitativo:
Si se tomó una evaluación a los alumnos y supera negativamente el 50\%, tengo que cuestionarme. Yo creo que el porcentaje aproximado puede ser un 10 , un $15 \%$ pero cuando lo supera, hay algo que no estamos haciendo bien (E1).

\section{b). Funciones de la evaluación}

Una de las funciones que E1 considera que cumplen las evaluaciones de los aprendizajes se reduce al ejercicio de constatar la presencia de ciertos repertorios de saberes teóricos y prácticos en los estudiantes, que le servirán como información para ir regulando aquello que ya han incorporado y aquello que les falta por adquirir.

La evaluación es para mí, la confirmación de la adquisición de alguna forma de los saberes. Vos pensás que esta es una materia, que es un ámbito de trabajo psicológico, dónde no tan sólo se evalúan los conocimientos, sino también se evalúa el procedimiento y lo actitudinal (E1).

Por otra parte, la evaluación debe contemplar los requerimientos afectivos e interpersonales de la formación profesional, no solo se limita a evaluar aquello que se ha enseñado de forma explícita por el docente.

Alguien que pasa por esto, si bien por ahí le van a faltar los seminarios, es casi un profesional. Entonces tiene que empezar a poder posicionarse desde ahí, y entonces el hecho, de ponerlo en situación con red en un caso, por ejemplo... para un caso que lo resuelva, le confirma qué es lo que sabe, y qué es lo que tiene que saber, si es que no lo sabe. $Y$ a nosotros también nos sirve, para medir qué es lo que le estamos transmitiendo y qué no y qué hay que reforzar (E1).

Pareciera que la evaluación cumple la función de chequear si los conocimientos, que le permitirían al alumno acercarse a la realidad, han sido incorporados. Pero esos conocimientos parecen estar dados de ante mano por el docente:

Para nosotros siempre es mirar, qué logró, qué le faltó, y si le faltó, por qué. Y a lo mejor hubo gen- 
te que no se comprometió. Para mí la evaluación final la tengo en el final. Ahí es donde yo veo... a mí me sirve también poder reconocer cómo está trabajando en los prácticos y se transmite esta idea de la profesión de la manera en qué yo como responsable de la cátedra entiendo (E1).

Por otra parte, las evaluaciones cumplen la función de brindar una información que se usará para ajustar el proceso de enseñanza y de aprendizaje:

A mitad de camino de la cursada, se le pregunta ¿qué dificultades ha encontrado? y ¿cómo se podrían modificar la propuesta? Eso nos nutre a nosotros, para saber, por ejemplo, si estamos yendo muy rápido, la bibliografía no es clara o es excesiva, etc. (E1).

Así pareciera que la evaluación denota una perspectiva evolutiva y uno de sus objetivos es proveer retroalimentación oportuna al estudiante. La retroinformación es crucial para el desarrollo del proceso formativo del estudiante, en lo referente a los logros buscados.

\section{c). Técnicas e instrumentos de evaluación}

Los instrumentos de evaluación de los aprendizajes propuestos por E1 son de lo más variados a lo largo de toda la cursada, esto está asociado al fuerte entronque de la evaluación con su propuesta pedagógica, así podemos leer que en su Plan de Trabajo figura la siguiente sentencia: "evaluación a lo largo de toda la cursada y a través de todas las actividades".

E1 propone un sistema de evaluación que aparenta ser ordenado según las tipologías basadas en la funcionalidad de las evaluaciones. Así parece haber constituido las evaluaciones a través de un sistema que incluye evaluaciones diagnósticas, sumativas, formativas y contínuas.

Cuando el alumno entra en los prácticos directamente se supone que se tiene que hacer una evaluación inicial con los alumnos. A mitad de camino de la cursada se le pregunta ¿qué dificultades ha encontrado?, ¿cómo se podrían modificar? y al final hay una evaluación también (E1).
Así las evaluaciones van dando una información continua a los docentes y a los alumnos. Por otra parte al final de la cursada se toma un examen escrito, lo que se conoce como parcial. Junto a esto se trabaja con una carpeta donde los alumnos van haciendo un análisis de un caso concreto que compete al área profesional de psicología jurídica.

Nosotros estamos haciendo de manera domiciliaria este año la defensa del caso. Que la trabajen como quieran, lo importante es que haya coherencia y el alumno termina con un informe integrador, de todas las instancias (E1).

Junto a esto se propone un examen final global oral.

\section{d). Articulación de la evaluación con el currículo}

E1 entiende que la evaluación está interconectada al currículo y articulada con la enseñanza. Ella da ejemplos de cómo a lo largo de los años en situaciones de evaluación han ido apareciendo inquietudes y demandas de los alumnos que sirvieron de información, usada luego para retroalimentar el currículo mismo.

Hemos ido intentando modificar, nos fuimos dando cuenta (...). Yo ahora estoy muy contenta con el modelo que tenemos en la cátedra, de cómo el alumno se acerca al conocimiento de lo que es la psicología jurídica. Porque tiene varias formas de entrar, los alumnos en su momento decían: "yo no vi nada en la práctica", entonces yo los ponía en situación, a ver como dramatizas esta cuestión, y decían no yo nunca vi nada, es la primera vez, nunca había salido al campo, a encontrarse con una realidad; este... y uno va escuchando también, en proporción a eso será lo que uno puede exigir. ¿Qué es lo que trae el alumno? (E1).

Es interesante ver cómo la articulación currículo, enseñanza y evaluación, no solo se da a través de un proceso de retroalimentación a largo plazo, sino que también es intercalada y pensada en la propuesta de plan de trabajo como una instancia que recorre toda la cursada: 
"si vos ves mis gráficos, de lo que es la cursada, está atravesada la evaluación en todo momento. Es decir no es una instancia compartimentada" (E1). En efecto:

A mitad de camino de la cursada, se le pregunta ¿qué dificultades (a los estudiantes) ha encontrado?, ¿cómo se podrían modificar?... Eso nos nutre a nosotros, para saber por ejemplo, si estamos yendo muy rápido, la bibliografía no es clara o es excesiva, etc. (E1).

Por otra parte, en las evaluaciones encuentran cabida los componentes que derivan de la enseñanza, del currículo, del ambiente de clase, del contexto, de la disponibilidad y características de los recursos didácticos y de los medios de aprendizajes.

Podemos extraer a modo tentativo de la lectura de la entrevista de E1 las siguientes categorías:

- Evaluación como acto de medición (concepción y funciones de la evaluación): se trata de corroborar si el estudiante aprendió o no lo enseñado por el docente.

- Evaluación como mecanismo de feedback (concepción y funciones de la evaluación): la evaluación aporta datos que permiten regular el proceso de adquisición del conocimiento.

- Funcionalidad de la evaluación (técnicas e instrumentos de evaluación): se organiza el sistema de evaluación según las tipologías de las funciones de estas. Se presentan varias opciones de instrumentos y se evalúa a lo largo de toda la cursada.

\section{La evaluación como examen de opción múltiple (E2)}

\section{a). Concepción general de la evaluación de los aprendizajes}

Los relatos de la E2 tienen la particularidad de estar enmarcados por su posicionamiento crítico con respecto a las instituciones educativas. De manera tal que se pueden trazar varios planos en su narración. E2 organiza su relato siendo consciente de la existencia de al menos dos de esos planos. Uno que se ubica temporalmente en su pasado y presente biográfico y es descripto con una coloración negativa. Y otro ubicado en un futuro en el cual deposita ideales. Es en función de este marco que E2 fundamenta sus creencias, decisiones y obrares.

E2 tiende a adjudicarle a la evaluación de los aprendizajes una coloración negativa. "En general pienso que son poco felices" (E2). A la hora de dar cuenta de sus dichos, aparece toda una serie de justificaciones, entre ellas figura el hecho de pensar las evaluaciones como formas de coerción donde la singularidad del docente encarna la función policíaca de las instituciones educativas. "De hecho, deben arrastrar alguna especie de criterio, no sé si llamarlo policial, o persecutorio, o de control, digamos. Me parece que de control, centralizado en una persona" (E2).

Comprender su visión requiere enmarcarla dentro de un sistema más amplio de pensamiento, a través del cual E2 da cuenta de su posicionamiento. Su discurso tiende a ordenarse en torno a la idea de la existencia de un sistema opresor que logra replicarse a través de un esquema de memes.

Yo creo que la memética promedio de los cerebros todavía es una memética que pide autoritarismo, pide verticalismo, pide referencias seguras, y eso lo hace arrastrar una hipocresía altamente dañina, para todos y no digo hipocresía voluntaria, digo hipocresía que está incita en los sistemas creenciales o mejor dicho en la memética que todavía está inserta en los cerebros, de esta tardía modernidad que todavía está demasiado penetrada por los vicios de la modernidad (E2).

Dentro de este marco, la tradición de evaluación de los aprendizajes se perfila como una de las formas donde el sistema opresor mejor logra operar. "Yo trato de cambiar eso en lo posible, pero el sistema exige que se hagan 
evaluaciones parciales, finales, recuperatorios, números o sea todo el sistema tiene esa enfermedad" (E2).

\section{b). Funciones de la evaluación}

Una de las funciones que E2 adjudica es la de control. Visualiza las tradiciones evaluativas como encarnadas por los docentes y siendo funcionales a un sistema social que limita las posibilidades del crecimiento del diálogo y del conocimiento. Por tanto, afirmó el entrevistado "que de hecho, deben de arrastrar alguna especie de criterio, no sé si llamarlo o policial o persecutorio o de control digamos. Me parece que de control, centralizado en una persona" (E2). Si bien deja en claro que está en contra de esta función de las evaluaciones, trata de moderar su discurso. Para ello intenta hacerlo entroncar dentro de un sistema más amplio de pensamiento, donde el diálogo y el encuentro intersubjetivo parecen ser los móviles centrales de la construcción del conocimiento.

No es que esté en contra de todo tipo de control, pero me parece que es mejor el control intersubjetivo y social. Por lo tanto me parece que habría que reformular lo que se llama evaluación. Tendrían que ser autoadministradas en un contexto de grupalidad dialogal, es decir, que las personas se den una alta a sí mismas, pero en el conjunto de la mirada de los demás, no un alta arbitraria caprichosa y subjetiva, sino que entre procesos colectivos y no centrados en un docente, centrado en la caparazón de la autoridad y demás. Hay que ir deconstruyendo todo el verticalismo por el que está atravesada nuestra sociedad (E2).

Una segunda función de las evaluaciones puede llegar a ser la de confirmarle al alumno que ha incorporado algún tipo de conocimiento. Pero rápidamente la desestima y se posiciona críticamente frente a esta posibilidad.

Algunos creerán que le sirve para chequear su estado de conocimiento (risas), pero me parece que se equivocan si creen eso. Estamos todavía impregnados de ceremoniales, ceremoniales en pavadas digamos, porque si ceremonializáramos más el diálogo, avanzaríamos muchos casilleros. Pero tenemos ceremonializada la listita de asistencia (E2).

Una tercera función de las evaluaciones es la de dar cumplimiento a las exigencias y tradiciones de las instituciones educativas "cumplo la función, la actividad del funcionario, no lo considero una evaluación verdadera digamos, lo considero un trámite con el que hay que satisfacer al sistema oficial en sus ceremoniales vacíos" (E2).

\section{c). Técnicas e instrumentos de evaluación}

E2 utiliza actualmente dos modalidades de evaluación. Por un lado evalúa a través de exámenes de opción múltiple. Pero una vez más su elección es justificada enmarcándola en un sistema metateórico más amplio.

Hacemos exámenes de opción múltiple o de preguntas semicerradas digamos, con una respuesta intersubjetivable, y con todo eso intentamos borrar la posibilidad de invasión del sistema por parte de la singularidad del docente, de su singularidad o de su arbitrio (E2).

Lo que busca a través de esta modalidad de evaluación es borrar la singularidad del docente, que puede contaminar su accionar a través de la replicación de sus esquemas meméticos dañinos ${ }^{1}$. Por otra parte, logra hacer encajar la materialización del diálogo, concretizándolo a través de conversaciones públicas donde todos pueden acceder a la corrección del examen. Es decir:

por ejemplo en nuestras cátedras jamás tenemos interacciones privadas con los estudiantes, sino que todas las interacciones las hacemos públicas o sea si hay que discutir el resultado de un examen, hacemos esa conversación a la vista de todos los demás (E2).

1 E2 se refiere a memética como una forma de entender la evolución cognitiva-cultural, de modo que la evaluación actúa como medición de la información de la trasmisión cultural. 
No obstante sus justificaciones, podemos ver que se terminan priorizando en los exámenes parciales, las respuestas escritas y principalmente aquellas que requieren marcar en vez de producir una respuesta. Por consiguiente, se enfatiza una concepción de la inteligencia no dinámica ni evolutiva, porque solo existe una respuesta correcta, identificando la evaluación con conceptos exclusivamente de medición y calificación.

Por otro lado, utiliza otra modalidad de evaluación que la presenta como una forma de evaluación más primaria y preferida por él. Aparece concretizada en situaciones específicas de enseñanza y de aprendizaje, y permite que docente y alumnos puedan ir haciendo un seguimiento del proceso de construir conocimiento "sirve mucho más una pregunta y una respuesta o la manifestación de una duda, una conversación, digamos, sirve mucho más que hacer toda una ceremonia" (E2). Además expresó:

Mi manera de evaluar es en las conversaciones en el aula, cuando formulo una pregunta y les digo cómo le explicarían esto a un lego... y entonces veo cómo lo explica y ahí es donde tengo un feedback sobre lo que está pasando. Después coincide con lo que pasa en los exámenes, pero los exámenes no me agregan nada (E2).

\section{d). Articulación con el currículo y la labor docente}

En lo que atañe a la articulación podemos ver cómo E2 deposita la posibilidad de su aplicación en un futuro ideal. Para E2 la evaluación debería ser"...algo continuo... un aprendizaje continuo, una evaluación continua. Creo que se usa ese concepto. Claro... yo creo que eso sería una evaluación continua. Pero tiene que ser una autoevaluación colectiva, continua" (E2). Pero resigna esta posibilidad por falta de recursos para lograrlo. Recursos materiales y humanos. No obstante, en la situación áulica intenta que la articulación se lleve a cabo, donde aparece más conciencia de la articula- ción que se da entre algunos problemas nodales de la disciplina propuestos por la cátedra, una forma conversacional de aprendizaje y una evaluación constante y con feedback inmediato. Esta forma de evaluar no está incluida en el plan de trabajos, sino que es una forma propia de accionar. Así dirá:

Que los estudiantes puedan resolver algunos problemas nodales, problemas que se dan al principio de la cursada. Mi sur, mi punto de referencia, es el planteo de un problema, que tiene la forma lingüística de una pregunta y su solución o soluciones. Eso es lo que yo creo que tiene que darse en el aula, habla constante con el estudiante, eso es lo que finalmente funciona como una evaluación. Tanto el que pregunta como el que está siendo preguntado, se dan cuenta de si puede o no responder, finalmente esa es la valuación. Es una coevaluación digamos, entre dos personas que argumentan y contraargumentar entre sí, una evaluación conjunta en equipo (E2).

Podemos extraer a modo tentativo de la lectura de la entrevista de E2 las siguientes categorías:

- Evaluación como sistema coercitivo (concepción y funciones de la evaluación): la evaluación es una forma de control al servicio de intereses de sistemas sociales más amplios.

- Evaluación como acto de medición (concepción y funciones de la evaluación): se trata de corroborar si el estudiante aprendió o no lo enseñado por el docente.

- Evaluación como mecanismo de feedback (concepción y funciones de la evaluación): la evaluación aporta datos que permiten regular el proceso de adquisición del conocimiento.

- La evaluación como reconocimiento y reproducción de lo aprendido (técnicas e instrumentos de evaluación): mediante examen de opción múltiple se pide el reconocimiento y verificación del conoci- 


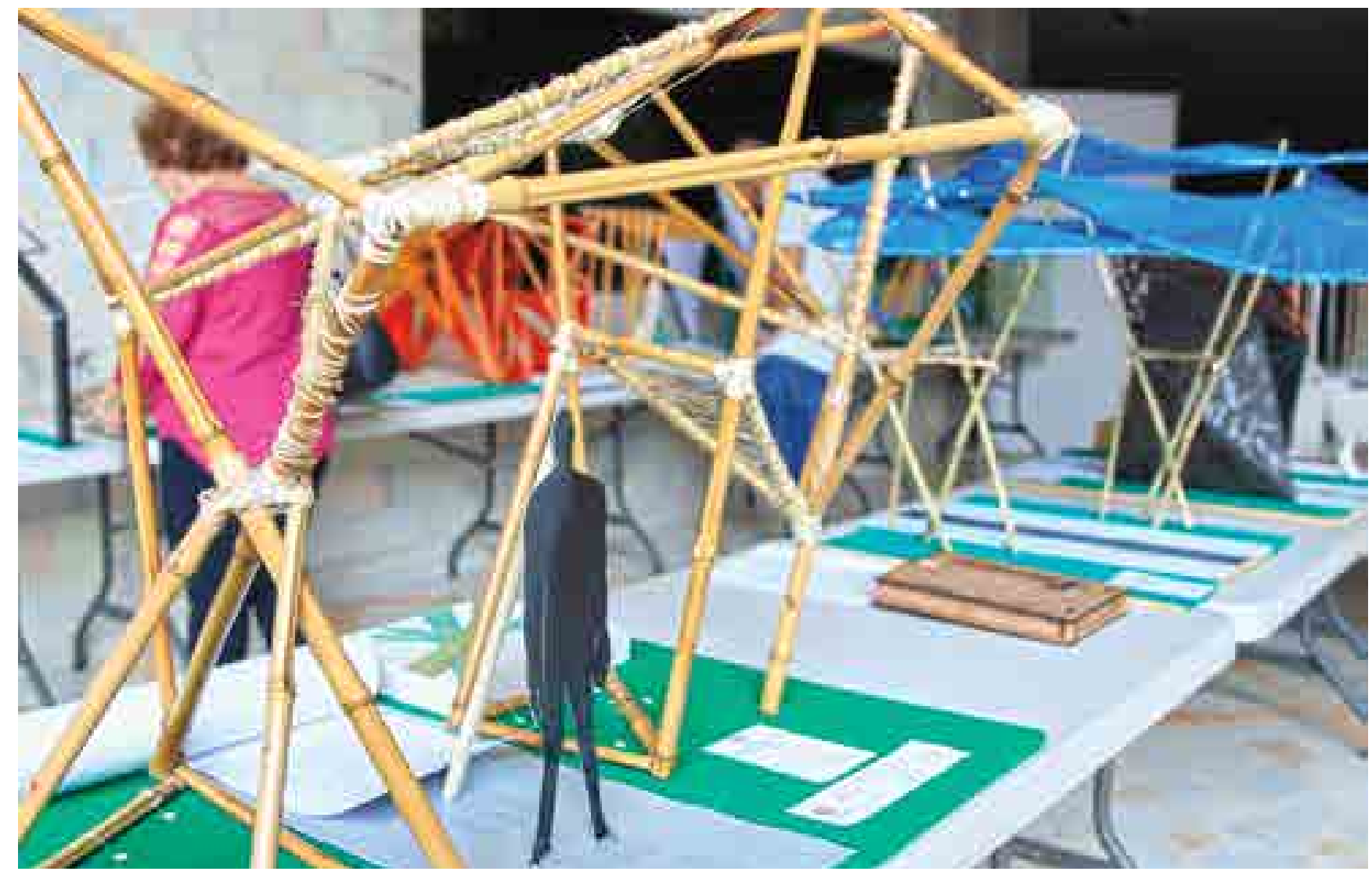

Exposición Maquetas.

miento enseñado por el docente. El examen es una instancia compartimentada al final del proceso de aprendizaje.

\section{La evaluación como motivador extrínseco (E3)}

\section{a). Concepción general de la evaluación de los aprendizajes}

E3 comienza su respuesta sobre la evaluación de los aprendizajes sincerando que es un área deficitaria en su formación y en su actividad reflexiva.

No tengo unos pensamientos muy conscientes. Me parece (largo silencio) que desconozco... me parece que es una falencia que tengo, desconozco bastante acerca de la evaluación de los aprendizajes, a pesar de que he hecho desde evaluaciones, podríamos decir más cuantitativas tipo opción múltiple, hasta cosas mucho más... cómo decirlo... más laxas o globales... (E3).
Esto se puede comprender más claramente si recordamos que la formación docente de E3 ha estado más emparentada con la práctica y la copia de modelos de sus propios docentes a través del aprendizaje implícito, que con la formación específica en docencia. Así, cuando se le pregunta acerca de su formación como docente responde. "Nada sistemático, pero sí hice algunos cursos de formación docente, uno de lectoescritura en la universidad, otros de formación de pedagogía universitaria pero nada sistemático" (E3).

En relación con lo arriba descripto, tal vez se pueda entender que la evaluación de los aprendizajes sea para él una actividad de menor valor dentro de las actividades pedagógico docentes. "Diría que es de menor importancia en mi consideración, en relación con otras, excepto para ver qué se aprendió, qué no se aprendió" (E3). 
E3 circunscribe las evaluaciones, poniendo énfasis en el seguimiento del proceso que el alumno recorre para el logro del objetivo de la cursada, que consiste en la entrega de un trabajo final. En ese sentido, "eso me parece que son evaluaciones bastante amplias, donde, en realidad, lo que yo evalúo es el acercamiento al tema, que se tenga interés en algo, que haya intentado entender algo y que haya trabajado" (E3).

De manera tal, que en su valoración se vuelve preponderante el proceso que realiza el alumno, donde E3 puede ir palpando qué tanto se implica este último en la producción del trabajo de cursada.

Me doy cuenta que me siento mucho más cómodo propiciando este tipo de evaluaciones, me parece que le sirve más al que le interesa, al que no le interesa es simplemente una monografía, toma dos o tres temas y trata de zafar (E3).

E3 considera que el desarrollo de este interés por temas particulares que despierten la curiosidad del alumno es una cuestión importante para tener en cuenta, en tanto pondera que esa es la actitud que debe tener un psicólogo hoy en día.

¿Cuál es mi rol aquí? ¿Controlar que esta persona haya aprendido lo que tiene que aprender? o que se haya acercado a la materia de algún modo y que le haya interesado algo y allá... por ahí no tiene todos los contenidos, pero tiene el interés por un par de temas que le gustaron? y no sé si eso no está mucho más cercano a la realidad del futuro profesional, antes de que conozca de pe a pa todos los contenidos de la materia (E3).

Por momentos pareciera ser que en la narrativa de E3 no hay un claro deslinde entre lo que sería la producción del trabajo y la evaluación de los aprendizajes en sí misma. Pero por otro lado, pareciera ser que hay un deslinde y que ese distinguir hace que E3 pueda tomar conciencia de cómo la evaluación atraviesa el proceso de aprendizaje brindando una recursividad informacional que repercute en la forma que piensa la estructura del currículo y su rol docente.

\section{b). Funciones de la evaluación}

E3 distingue tres funciones que cumpliría la evaluación de los aprendizajes. Primero aparece la función de dar cumplimiento con lo requerido por las instituciones y lo establecido. "Bueno una es la de ser parte de un sistema que está armado y organizado de un determinado modo, que tiene ciertas reglas que me exceden a mí" (E3). En este punto es interesante recordar que considera las evaluaciones de los aprendizajes como actividades de menor valor, en comparación a otras como podría ser la enseñanza. De esta manera es comprensible que considere que una de las funciones es la de cumplir con los requerimientos del sistema universitario y sus tradiciones.

\section{También especifica una segunda función}

La otra me parece, que es la de... de algún modo, acercar al estudiante a realizar un trabajo, que no necesariamente va a ser por motivación intrínseca. A lo mejor funciona como motivación extrínseca, para la posibilidad de trabajar y estudiar sobre algo. Me parece que cumple una función de control, de motivación extrínseca (E3).

Aquí resalta la función, si se quiere, más coercitiva y controladora de la evaluación de los aprendizajes. Según esta idea las evaluaciones servirían para que los alumnos se aboquen a la asimilación de los saberes y de sus responsabilidades. Sobre esta función parece tener un posicionamiento valorativo, ambivalente, pues por momentos parece valorarlo negativamente:

En la función docente siempre está este tema ¿cuál es mi rol aquí? ¿Controlar que esta persona haya aprendido, 'lo que tiene que aprender' o que se haya acercado a la materia de algún modo y que le haya interesado algo y allá... (E3).

Pero por otro lado, finalmente, parece resignar adjudicarle una coloración totalmente negativa a esta función, pues finalmente piensa que por el momento es algo que funciona, que se vuelve necesario sostener y resignarse (al menos por el momento). 
... Sí... sí... yo diría que sí. Pienso que es una especie de transición, una evolución de todos como sociedad, como personas. Habitualmente los factores coercitivos siguen siendo importantes en las sociedades, cumplen funciones, lo ideal sería que no existieran y creo que habría que ir trabajando para que no existan más, pero mientras tanto los sistemas morales y jurídicos y de control siguen operando (E3).

Por otra parte la evaluación de los aprendizajes tiene la función de devolver información al docente para que vaya ajustando su propia labor.

\section{c). Técnicas e instrumentos de evaluación}

Para E3 la evaluación coincide con el proceso de elaborar un trabajo tipo monográfico, donde se desarrolle un tema de interés para el alumno, así, a través de esta forma de evaluar se accede al camino que el alumno realiza para conseguir el objetivo.

Mira tienen que hacer un trabajo, que tienen que presentar en cualquier momento del año y tienen dos plataformas virtuales, un correo electrónico y una página en Facebook. En la página de Facebook intercambiamos todos información y cuestiones acerca de cómo debe hacerse el trabajo, hay una conexión entre los alumnos y también conmigo. Por correo electrónico directamente se conectan conmigo y yo les voy asesorando, desde que elige el tema que les ha interesado, hasta que el informe está aprobado (E3).

De esta manera, el proceso de seguimiento de la elaboración de la monografía junto con la revisión que $\mathrm{E} 3$ hace de esa misma una vez finalizada, son las evaluaciones en tanto que práctica concreta propiamente dicha, donde E3 obtiene los datos para emitir el juicio evaluativo. Es interesante que E3 haya propuesto para el transcurso de la cursada un ejercicio de intercambio entre alumnos en el cual intercambian información y se hacen señalamientos y aportes mutuos y que E3 no lo haya considerado como una forma de evaluación a incorporar en su plan, sino que lo vea como una forma de aprendizaje vicario.
Es que nunca lo había pensado como evaluación, en realidad yo lo pienso más como una instancia de aprendizaje en realidad. Ahora que lo pienso parece ser que está muy ligado con la evaluación, donde parece ser que a la vez se co-evalúan. Pero en realidad yo lo había pensado como una instancia de aprendizaje. Pensando en esto del aprendizaje vicario, que se da entre pares, cómo le sirve a cada uno poder ver lo que el otro ha hecho y poder fijarse qué podría aportar (E3).

\section{d). Articulación con el currículo y la labor docente}

Al igual que con los otros dos entrevistados E3 piensa en una articulación según la cual, en la medida que transcurre el proceso de evaluación recibe un feedback que le permite ir ajustando su práctica docente.

Habitualmente para repensar si están resultando claros los puntos que a mí me interesan, si quedan claros contenidos mínimos. Para repensar la manera de... o la importancia que le voy a dar en futuras cursadas, a los temas que yo quiero que se cumplan, porque quiero que la gente se interese. Este... me da un dato, con el que después puedo ver, qué estrategia pedagógica debo cambiar o sobre qué acentuar más y poner mayor énfasis en futuras cursadas (E3).

Podemos extraer a modo tentativo de la lectura de la entrevista de E3 las siguientes categorías:

- Evaluación como motivación extrínseca (concepción y funciones): la evaluación se vuelve el móvil para que los estudiantes aprendan y estudien en un sistema de recompensas y castigos.

- Evaluación como mecanismo de feedback (concepción y funciones de la evaluación): la evaluación da un dato que permite regular el proceso de adquisición del conocimiento.

- Evaluación sobre el proceso de elaboración monográfico (técnicas e instrumentos de evaluación): se fijan criterios de eva- 
luación teniendo como objeto el proceso y la posibilidad de varias modalidades de elaboración, pero siempre en función de un modelo establecido previo.

\section{Conclusiones}

De las múltiples posibilidades de entrecruzamiento de estas tres voces docentes, hemos hecho foco recortando lo que podríamos llamar tres grandes ejes. Esos ejes están atravesados por los puntos de análisis más arriba descriptos. Un primer eje en el cual se aborda la relación que se establece en cada una de las entrevistas entre el valor que le otorgan a la evaluación de los aprendizajes y las propuestas de evaluación que se materializan durante las cursadas. Un segundo eje al que podríamos llamar la evaluación oculta, pensado tal vez en una forma de evaluación que no aparece "escrita", ni integrada en los planes de trabajo prácticos. Y, finalmente, un tercer eje donde indagamos acerca de los cambios, en términos de rupturas y continuidades, que han introducido en la evaluación de los aprendizajes los docentes a lo largo de los años.

\section{Primer eje}

El diseño y la puesta en práctica de los sistemas de evaluación propuestos por cada uno de los docentes, tiende a ligarse a las valoraciones particulares que cada uno de ellos verbaliza sobre la evaluación de los aprendizajes. De manera tal que variables como la complejidad, la articulación y el trazado de las formas de evaluación son distintas en función de que las mismas sean consideradas de mayor o menor importancia dentro de las actividades pedagógico-docentes de los entrevistados.

E1, a diferencia de E2 y E3, valora la evaluación de los aprendizajes de manera positiva y le otorga un lugar de importancia central en su actividad docente. E3 por el contrario verbaliza que en su consideración, las evaluaciones de los aprendizajes son actividades de menor importancia dentro de las actividades educativas, aunque reconoce que tal vez se deba a un déficit en su formación docente. En cambio E2 tiende a valorar la tradición de evaluación de los aprendizajes de manera totalmente negativa.

Así podemos ver cómo estas valoraciones resuenan y se retroalimentan recursivamente con el trazado de los sistemas concretos de evaluación a lo largo de la cursada. E1 presenta un sistema de evaluación donde las evaluaciones no se reducen a la situación de examen, sino que como E1 dice, atraviesa toda la cursada y se articula en varios niveles con la enseñanza y el aprendizaje.

En cambio la propuesta concreta de evaluación que E2 hace para la cursada, aparece emparentada a las formas tradicionales, donde se reduce la situación de examen a un compartimento estanco y donde parece privilegiarse el dominio de los contenidos del programa de estudio. Así esta modalidad termina identificando la evaluación con conceptos exclusivamente de medición y calificación, restándole el sentido formativo a la misma. A través de estos instrumentos de evaluación se contrabandea una concepción según la cual aprender es reproducir la realidad y el conocimiento es la única vía capaz de cumplir con la copia exacta de la realidad.

E3 afirma, que en su consideración, la evaluación de los aprendizajes es una práctica de menor valor dentro de las prácticas docentes. Esta valoración se corresponde con una concepción de la evaluación y una propuesta concreta de evaluación, en la que esta coincide con la corrección progresiva y final de la elaboración de una monografía. Donde la evaluación tiene una función de motivador extrínseco, para la realización del trabajo. Parecería entonces que es necesario activar en ellos los procesos internos de atención, interés y comprensión para lograr los resultados esperados (sean estos conocimientos o habilidades). 


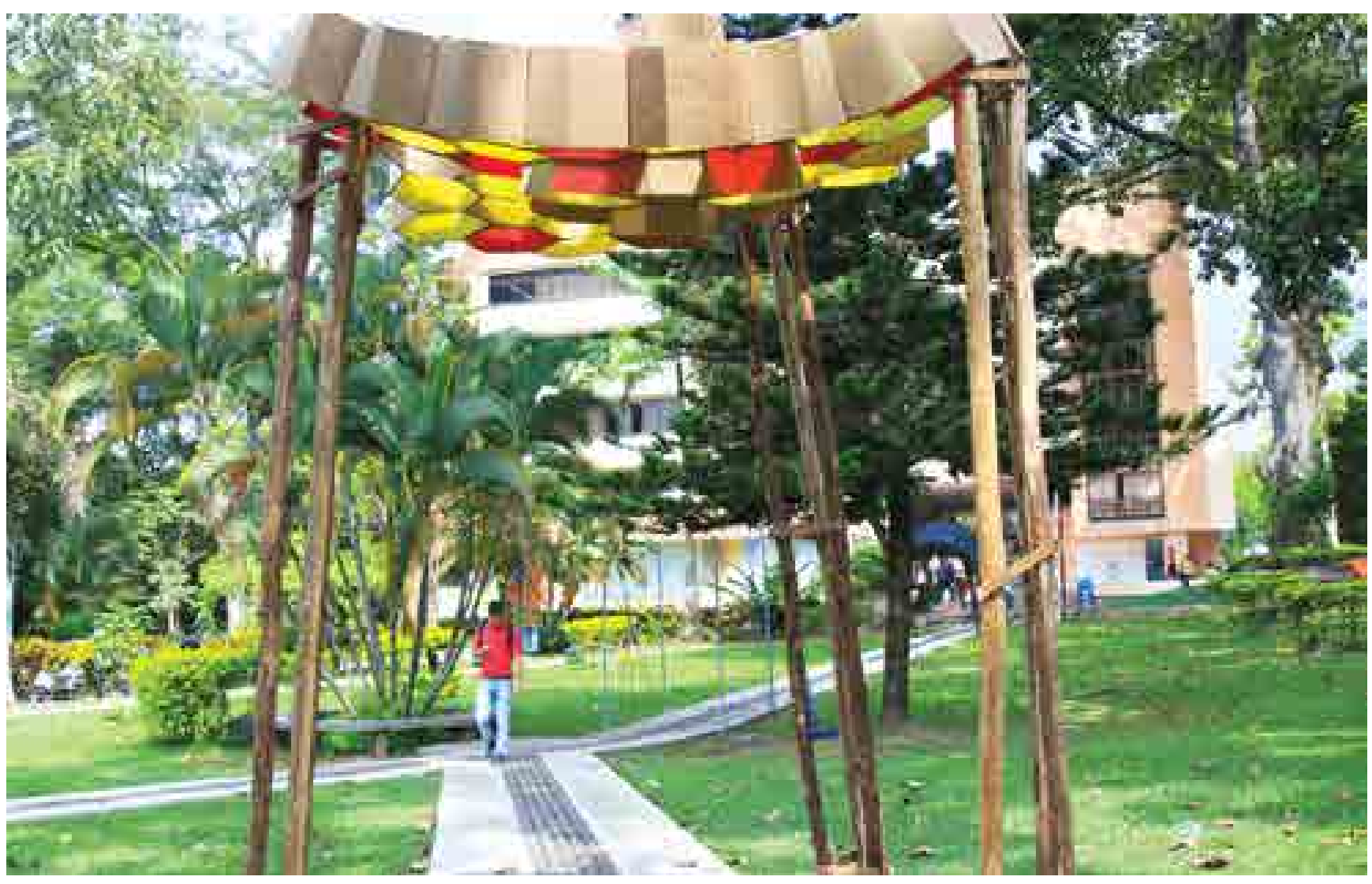

Proyecto Panal de Abejas.

\section{Segundo eje}

Como segundo eje del entrecruzamiento de las tres voces, reconocemos en los entrevistados una recurrencia similar. Los tres terminan manifestando (o tal vez confesando), que la verdadera evaluación la realizan cara a cara con los alumnos en un encuentro conversacional donde fluye el pensamiento. Donde evaluación, enseñanza y aprendizaje suceden casi en simultáneo.

\section{E1 dice:}

Para mí la evaluación final la tengo en el final. Ahí es donde yo veo... Yo en general trato de repreguntar, en general repregunto y cuando no saben también. Los ayudantes dicen "vos le das mucho". Yo por ejemplo, intento hacerte pensar, suponte con la nueva legislación de minoridad. Entonces si ese es un lugar del psicólogo jurídico, entonces ¿cuáles serían los ámbitos de trabajo? Dicen bueno los servicios locales, y le digo ¿a dónde pertenecen los servicios locales? Entonces me miran, les digo ¿cuántos poderes hay en la Argentina? Me dicen ¿qué poderes? Bueno el poder ejecutivo, el poder judicial... ¿Qué dice el nuevo paradigma? ¿Por qué fueron creadas nuevas instituciones respecto a la niñez?, bueno entonces esa es la idea, pensar qué poderes públicos hay, ¿el psicólogo jurídico con quienes va a trabajar?, con aquello que están bajo potestad jurisdiccional ¿Qué quiere decir eso? Van a estar bajo el ala de un juez y los jueces donde trabajan... bueno entonces yo llego a todo eso. A mí me ha pasado por ejemplo, que no pudieran entender qué es la psicología jurídica de entrada, y entonces me dicen ¿por esto? Yo soy por lo general de repreguntar mucho, a mí me parece que si vos te levantas de la mesa bochado, tenés que saber por qué y dónde sentís que te dieron todas las opciones. Mirá estás confuso en esto, no entendés lo otro (E1).

Por otra parte y en un lineamiento similar E2 narra: 
La única manera dialogal de evaluarse me parece a mí, sería una manera continua de diálogo, de principio a fin de la cursada... Mi manera de evaluar es en las conversaciones en el aula, cuando formulo una pregunta y les digo cómo le explicarían esto a un lego... y entonces veo cómo lo explican y ahí es donde tengo un feedback sobre lo que está pasando. Después coincide con lo que pasa en los exámenes, pero los exámenes no me agregan nada... eso es lo que finalmente funciona como una evaluación. Tanto el que pregunta como el que está siendo preguntado, se dan cuenta de si puede o no responder, finalmente esa es la evaluación (E2).

Finalmente E3 dice: "Hay estudiantes que consultan cinco veces, hay estudiantes que consultan tres y hay estudiantes que no consultan nunca, y mandan el trabajo final y lo hicieron bien y de acuerdo con los requerimientos de las pautas..." (E3).

Ante la pregunta de si considera que estas consultas evalúan diría:

Sí claro. Es sobre todo en el aspecto actitudinal. Habitualmente el alumno que consulta cinco veces, es una persona que le interesa el trabajo. Entonces me pregunta sobre el tema de interés... ¿qué te parece... podría ir por acá? Los oriento de acuerdo con mi parecer, orientó hacia dónde puede ir a buscar información, de acuerdo con mi parecer... (E3).

Es muy interesante ver cómo también hay una recurrencia en los tres entrevistados, en remitir esta práctica a componentes bibliográficos que tienen una fuerte carga emocional: Así, por ejemplo, E1 adjudica la transformación de su práctica y la incorporación de su estilo de repreguntar en la búsqueda del sentido, a la experiencia que tuvo en ocasión de transitar por una especialización en docencia universitaria y de haber tenido encuentros con una docente, a la cual recuerda con admiración.

A mí me sirvió hacer una especialización, yo creo que con esto de la narración, de la anécdota... yo no sé si tuviste una profesora SOUTO... que llegaba y entonces decía... bueno llegué a Mar del
Plata... tomé el taxi. El taxista me decía que acá había habido muchos homicidios... estuvimos hablando entonces... Bueno hoy vamos al ver tal cosa... entonces cuando terminaba la clase eso dijo... bueno yo cuando llegué les conté la anécdota del taxista, porque esto me dio pie para esto... para esto otro... es como que fundamentaba el porqué de cada cosa. Eso a mí me sirvió, me sirvió para saber que las cosas no son porque sí, que todo tiene un sentido. Entonces que la narración es importante para entender el caso, que te permite llevar el meterte más sin querer en lo conceptual, pero a partir del ejemplo. Así que yo creo que me ha servido de alguna manera, me sirvió para poner cosas en la práctica (E1).

En E2 sucede algo similar. Podemos ver cómo esa evaluación dialogal de la que habla, puede rastrearse a través de su relato hasta su época de estudiante. Así su evaluación ideal coincide con las experiencias vividas en ocasión de haber sido evaluado por los que son sus docentes memorables, aquellos a los que admira, los que logran modificar el tono de su voz y pausan su relato.

La verdad que siempre padecí ser evaluado, salvo algunas veces que, el que tenía enfrente, era una persona muy admirada. Me pasó con Vilanova, me pasó con Serroni Copello, que era una satisfacción la reunión conversacional. No sé si lo vivía como una evaluación, si era un tipo de evaluación donde siempre ganabas, porque si recibías el desacuerdo del otro ganabas y si recibías el acuerdo del otro también ganabas, o sea eran experiencias hermosas. Pero no por evaluativas, sino por el encuentro interpersonal. Lo verdaderamente bueno era eso, la evaluación era el mal y que estaba mitigado por el encuentro (E2).

En el relato que E3 hace de su experiencia de haber sido evaluado en ocasión de su defensa de tesis de doctorado, podemos ver que se encuentran los componentes más valorados de su evaluación ideal. Describiéndola como un encuentro intersubjetivo donde decanta un intercambio similar a una charla.

Sí, cuando defendí mi tesis doctoral, fue una buena experiencia. Porque primero fui escuchado por gente que entendía del tema del cual estaba 
hablando, además esta gente tenía interés por lo que se estaba exponiendo, eso hacía que sus preguntas y sus contestaciones se fueran transformando en una charla, donde hubo, por ejemplo algunas sugerencias críticas con respecto a cuestiones de mi tesis, donde yo sentía que estaban haciendo aportes, más que una búsqueda de ver dónde puedo pellizcar (E2).

\section{Tercer eje}

Como tercer punto de comparación entre los entrevistados nos remitimos a los cambios que han introducido a lo largo de los años en sus sistemas de evaluación. Es interesante ver cómo, en los tres entrevistados, se vuelve difícil deslindar los cambios que dicen haber introducido en los sistemas de evaluación con lo que serían más bien cambios en sistemas más amplios que incluyen cambios de currículo, didáctica, aprendizajes y evaluaciones.

E1 ha ido introduciendo cambios a lo largo de los años. El principal móvil para incorporarlos han sido las demandas del alumnado, que fueron comentando la falta de contacto con la práctica profesional. De manera tal que se agregaron carpetas, donde se abordan casos concretos y donde los docentes evalúan a través de un seguimiento donde se van haciendo señalamientos.

Hemos ido intentando modificar..., nos fuimos dando cuenta... el alumno nos dice: ¿la práctica dónde está?... Yo ahora estoy muy contenta, con el modelo que tenemos en la cátedra, de cómo el alumno se acerca al conocimiento de lo que es la psicología jurídica. Porque tiene varias formas de entrar, los alumnos en su momento decían: "yo no vi nada en la práctica", entonces yo los ponía en situación, a ver cómo dramatizas esta cuestión, y decían no yo nunca vi nada, es la primera vez, nunca había salido al campo, a encontrarse con una realidad; este... y uno va escuchando también, en proporción a eso será lo que uno puede exigir. ¿Qué es lo que trae el alumno?... Nosotros estamos haciendo de manera domiciliaria este año la defensa del caso. Que la trabajen como quieran, lo importante es que haya coherencia y a partir de ahí se trabaja con el alumno, en la medida en que haya un planteo coherente, o no. Y se le devuelve la aprobación o desde el cuestionamiento que lo tenga que volver a hacer. Para nosotros siempre es mirar, qué logró, qué le faltó, y si le faltó, por qué (E1).

E2 intentó introducir cambios en su sistema de evaluación, buscando acercarse a una modalidad que permitiera el encuentro dialogal entre los alumnos y los docentes, pero su intento se vio frustrado. En sus palabras:

Hemos hecho intentos de evaluar de manera distinta, por ejemplo con coloquios en el marco de un coloquio... pero lo que descubrimos es que eso no funciona como evaluación, porque el estudiante va a ese lugar a tratar de responderle al docente. De hecho hay estudios que apoyan eso... que los estudiantes aprenden más cómo responderle al docente, que el aprendizaje de la materia de la que se trata. Se trata de aprender estrategias de respuesta para sobrevivir ante esa prueba, que se les pone, aprender a resolver el examen... entonces eso es lo que encontré en esos coloquios, el estudiante va a zafar. Comprensiblemente además, porque el sistema le pide eso. Entonces creo que la mejor alternativa es la opción múltiple, son lo más objetivas posibles, en el sentido de intersubjetivable (E2).

Sus intentos frustrados de introducir modificaciones que fueran armónicas con su concepción del proceso de producir conocimientos (a través del diálogo), fueron acompañadas de una fuerte carga emocional negativa, así dirá ante la pregunta sobre qué sentía en las evaluaciones a través del coloquio:

Desolación, tristeza, pena por todo el sistema, una pena muy grande por todos. En parte por uno, por estar ahí adentro y no estar pudiendo transformarlo. Entonces sentís la impotencia de ser una pieza en este sistema, que está funcionando mal, gravemente. Entonces los sentimientos, bueno la parte de sentimientos es dura (E2).

E3 al asumir la cátedra introdujo cambios en lo que atañe a las posibilidades de presentación del trabajo monográfico a ser evaluado, así dirá: 
Cuando asumí la cátedra, lo que hice fue que se ampliaran las posibilidades de presentación, antes estaban reducidas a presentar una especie de monografía o algo así y yo ahora se los amplié para que se acerquen a grupos de investigación o extensión, dónde puede ser parte de la presentación del trabajo, por ejemplo, que cuenten su experiencia acerca de un grupo de estos, que les sugirieron, que les contaron, que les interesa, siempre tratando de partir del interés de ellos, y eso me parece que son evaluaciones bastante amplias... (E3).

\section{Referencias}

Álvarez M, J. M. (2001). Evaluar para conocer, examinar para excluir. Madrid: Morata.

Bain, K. (2007). ¿Cómo evalúan a sus estudiantes y a sí mismos? En Lo que hacen los mejores profesores universitarios. Publicaciones de la Universidad de Valencia, Editado en Barcelona.

Bain, K. (2012). ¿Qué es la buena enseñanza? Revista de Educación de la Facultad de Humanidades, No. 4. Mar del Plata, UNMdP. Recuperado de http://fh.mdp.edu.ar/ revistas/index.php/r_educ/article/view/85/148

Bakker, L., y López, M. (2010). Evaluación de los aprendizajes en la asignatura Biologia Humana de la Facultad de Psicología: en búsqueda de una práctica consensuada. En: Porta, L. Docencia Universitaria: Currículo, enseñanza y evaluación. Mar del Plata, UNMdP.

Bolívar, A., y Fernández, D. (2001). La investigación biográfico-narrativa en educación enfoque y metodología. Barcelona: Ed. Muralla.

Bruner, J. (1998). Realidad mental, mundos posibles. Barcelona: Gedisa.

Camillioni, A. (2010). La validez de la enseñanza y la evaluación. En Rebeca Anijovich (comp.). La evaluación significativa.

Camillioni, A., y Cols, E. (2010). La problemática de la investigación didáctica: el caso de una investigación sobre formatos de evaluación de los aprendizajes y sus relaciones con las modalidades de estudio de alumnos universitarios. En Catalina Wainerman. El quehacer de la investigación en educación. Buenos Aires: Manantial.

Celman, S. (1998). ¿Es posible mejorar la evaluación y transformarla en una herramienta de conocimiento? En La evaluación de los aprendizajes en el debate didáctico contemporáneo. Buenos Aires: Paidós.

Celman, S. (2003). Evaluación de los aprendizajes universitarios. Más allá de la acreditación. Universidad Nacional del Sur.

Cols, E. B. (2009). Introducción. La evaluación de los aprendizajes como objeto de estudio y campo de prácticas. [En línea] Archivos de Ciencias de la Educación (4a. época), 3(3).
De Vincenzi, A. (2009). Concepciones de enseñanza y su relación con las prácticas docentes: un estudio con profesores universitarios. Educación y Educadores. 12(2), 87-101.

Di Domenico, C. y Vilanova, A. (1999). Formación de psicólogos en el Mercosur. Mar del Plata: Universidad Nacional de Mar del Plata.

Gadamer, H. (2001). Verdad y método I. Salamanca. Sígueme.

Goodson, I. (1992). Studying teachers Lives. Londres: Routledge.

Hubbard, R. S., y Power, B. M. (1999). Living the questions: A guide for teacher-researchers. Portland, Maine: Stenhouse.

Jackson, P. (2002). La vida en las aulas. Nueva introducción del autor. Madrid: Morata.

Litwin, E. (1998). Las configuraciones didácticas. Una nueva agenda para la enseñanza superior. Buenos Aires: Paidós.

Litwin, E. (2008). El oficio de enseñar: condiciones y contextos. Buenos Aires: Paidós.

McEwan, H., y Egan, K. (1998). La narrativa en la enseñanza, el aprendizaje y la investigación. Buenos Aires: Amorrortu.

Marrero, J. (1993). Las teorías implícitas del profesorado: vínculo entre la cultura y la práctica de la enseñanza. En Rodrigo, M., Rodríguez, A., y Marrero, J. Las teorías implícitas. Una aproximación al conocimiento cotidiano. Madrid: Visor.

Montero, M. (2001). La construcción del conocimiento en la enseñanza. En C. Marcelo (comp.). La función docente, (pp. 47-83). Madrid: Síntesis.

Moya, L. (2012). Análisis de la formación básica de carreras de psicología de universidades públicas: un estudio comparativo. Anuario de Proyectos e Informes de Becarios de Investigación de la Facultad de Psicología de la Universidad Nacional de Mar del Plata, 9, 710-718.

Porta, L., Sarasa, M. y Álvarez, Z. (2010, julio). La investigación narrativa en la enseñanza: las buenas prácticas y las biografías de los profesores memorables. En Revista de Educación, Año 1 - Núm. 1. Facultad de Humanidades. UNMDP.

Porta, L. (2017). La narrativa biográfica como magma de significaciones y cristalización de sentidos. Conferencia de Apertura de las II Fábrica de Ideas (Historias y Prácticas). Mar del Plata, 7, 8 y 9 de septiembre.

Recalt, A. (2018). Relatos de profesores acerca de la evaluación de los aprendizajes en la Facultad de Psicología de la Universidad Nacional de Mar del Plata. Trabajo Profesional en Docencia Universitaria. Mar del Plata, UNMdP.

Yedaide, M., Álvarez, Z., y Porta, L. (2015). La investigación narrativa como moción epistémico-político. En Revista Científico Guillermo de Ockham, 13(1).

\section{Entrevistas}

E1. Entrevista realizada a la titular de la materia Psicología Jurídica, por Adrián Recalt. Mayo 2017.

E2. Entrevista realizada al adjunto a cargo de la materia Epistemología de la Psicología, por Ardían Recalt. Septiembre 2017.

E3. Entrevista realizada al titular de la materia Núcleos Problemáticos, por Adrián Recalt. Octubre 2017. 